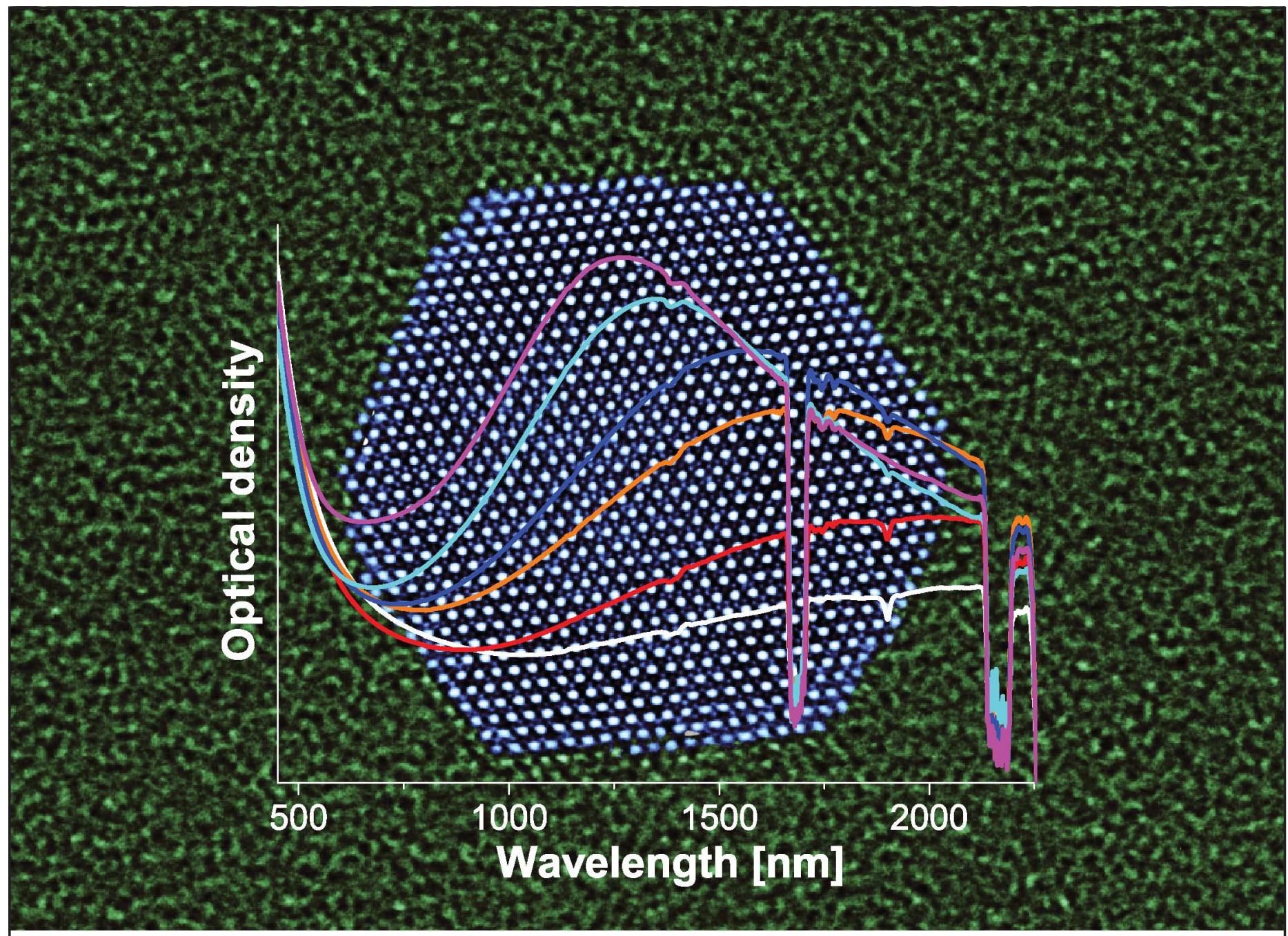

Showcasing research from the recipient of the 2011 Journal of Materials Chemistry Lectureship.

Title: Colloidal $\mathrm{Cu}_{2-x}\left(\mathrm{~S}_{y} \mathrm{Se}_{1-y}\right)$ alloy nanocrystals with controllable crystal phase: synthesis, plasmonic properties, cation exchange and electrochemical lithiation

Cubic and hexagonal phase $\mathrm{Cu}_{2-x}\left(\mathrm{~S}_{y} \mathrm{Se}_{1-y}\right)$ alloy nanocrystals, with a well-defined near-infrared valence band plasmon resonance, were transformed in the corresponding $\mathrm{Cd}$-based alloy nanocrystals, with the comparable $\mathrm{S}_{y} \mathrm{Se}_{1-y}$ stoichiometry, by cation exchange preserving the original crystal structure. Cubic $\mathrm{Cu}_{2-x}\left(\mathrm{~S}_{0.5} \mathrm{Se}_{0.5}\right)$ nanocrystals were then evaluated as anode material in Li-ion batteries.

As featured in:

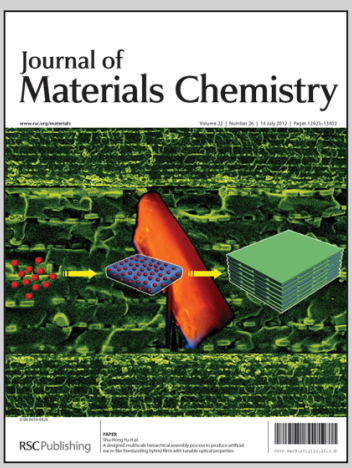

See E. Dilena et al.,

J. Mater. Chem., 2012, 22, 13023. 


\title{
Materials Chemistry
}

Cite this: J. Mater. Chem., 2012, 22, 13023

www.rsc.org/materials

PAPER

\section{Colloidal $\mathrm{Cu}_{2-x}\left(\mathrm{~S}_{y} \mathrm{Se}_{1-y}\right)$ alloy nanocrystals with controllable crystal phase: synthesis, plasmonic properties, cation exchange and electrochemical lithiation $\dagger$}

\author{
Enrico Dilena, $\leftarrow^{a}$ Dirk Dorfs, $\uparrow^{a b}$ Chandramohan George, $\dagger^{a}$ Karol Miszta,,${ }^{a}$ Mauro Povia, ${ }^{a}$ Alessandro Genovese, ${ }^{a}$ \\ Alberto Casu, ${ }^{a}$ Mirko Prato ${ }^{a}$ and Liberato Manna ${ }^{* a}$
}

Received 9th February 2012, Accepted 11th April 2012

DOI: $10.1039 / \mathrm{c} 2 \mathrm{jm} 30788 \mathrm{j}$

We report synthetic routes to both cubic and hexagonal phase $\mathrm{Cu}_{2-x}\left(\mathrm{~S}_{y} \mathrm{Se}_{1-y}\right)$ alloy nanocrystals exhibiting a well-defined near-infrared valence band plasmon resonance, the spectral position of which is dependent mainly on $x$, i.e. on $\mathrm{Cu}$ stoichiometry, and to a lesser extent on the crystal phase of the NCs. For cubic $\mathrm{Cu}_{2-x}\left(\mathrm{~S}_{y} \mathrm{Se}_{1-y}\right)$ nanocrystals $y$ could be varied in the 0.4-0.6 range, while for hexagonal nanocrystals $y$ could be varied in the $0.3-0.7$ range. Furthermore, the $\mathrm{Cu}_{2-x}\left(\mathrm{~S}_{y} \mathrm{Se}_{1-y}\right)$ nanocrystals could be transformed into the corresponding Cd-based alloy nanocrystals with comparable $\mathrm{S}_{y} \mathrm{Se}_{1-y}$ stoichiometry, by cation exchange. The crystal phase of the resulting $\mathrm{Cd}\left(\mathrm{S}_{y} \mathrm{Se}_{1-y}\right)$ nanocrystals was either cubic or hexagonal, depending on the phase of the starting nanocrystals. One sample of cubic $\mathrm{Cu}_{2-x}\left(\mathrm{~S}_{y} \mathrm{Se}_{1-y}\right)$ nanocrystals, with $\mathrm{S}_{0.5} \mathrm{Se}_{0.5}$ chalcogenide stoichiometry, was then evaluated as the anode material in Li-ion batteries. The nanocrystals were capable of undergoing lithiation/delithiation via a displacement/conversion reaction ( $\mathrm{Cu}$ to $\mathrm{Li}$ and vice versa) in a partially reversible manner.

\section{Introduction}

Over the last few years, considerable effort has been put into the synthesis of environmentally friendly semiconductor nanomaterials. Among them, Cu-based nanocrystals (NCs) such as copper chalcogenides have attracted particular attention as possible alternative materials to the more toxic, Cd-based counterparts. ${ }^{1,2}$ Also NCs of ternary and quaternary chalcogenides containing copper together with cations such as $\mathrm{Zn}$, In and Ga have been synthesized. ${ }^{3,4}$ One strength of these materials, besides their lower toxicity, is that a fine tuning of their optical properties can be achieved by controlling the chemical compositions and NC size, which makes them promising for low cost fabrication of thin film solar cells and LEDs. ${ }^{3,5}$ As an additional degree of freedom in varying the chemical composition of chalcogenide-based materials, more than one chalcogenide species can be present in the lattice, for example S and Se. To date, several colloidal NCs of mixed metal "sulfides-selenides" have been reported, for example $\mathrm{HgS}_{y} \mathrm{Se}_{1-y}$, $\mathrm{ZnS}_{y} \mathrm{Se}_{1-y},{ }^{7} \quad \mathrm{SnS}_{y} \mathrm{Se}_{1-y},{ }^{8} \quad \mathrm{CdS}_{y} \mathrm{Se}_{1-y},{ }^{9} \quad \mathrm{PbS}_{y} \mathrm{Se}_{1-y},{ }^{10} \quad \mathrm{CuIn}-$ $\left(\mathrm{S}_{y} \mathrm{Se}_{1-y}\right)_{2},{ }^{11} \mathrm{Cu}_{x} \mathrm{Fe}_{4} \mathrm{Sn}_{12}\left(\mathrm{~S}_{y} \mathrm{Se}_{1-y}\right)_{32}{ }^{12}$ and $\mathrm{Cu}_{2} \mathrm{ZnSn}\left(\mathrm{S}_{y} \mathrm{Se}_{1-y}\right)_{4} \cdot{ }^{13}$

${ }^{a}$ Istituto Italiano di Tecnologia, Via Morego 30, 16163 Genova, Italy. E-mail: liberato.manna@iit.it; Tel: +3901071781502

${ }^{b}$ Institut für Physikalische Chemie und Elektrochemie, Leibniz Universität Hannover, 30167 Hannover, Germany

$\uparrow$ Electronic supplementary information (ESI) available: Additional data on electron microscopy analysis; additional electro-chemical data and optical absorption spectra of a sample of alloy NCs at several oxidation stages. See DOI: 10.1039/c2jm30788j

\$ These people contributed equally to this work
On the other hand, the ability to control the crystal phase and to obtain NCs in phases that were previously non-accessible is also quite relevant (see for example recent works on wurtzite $\mathrm{Cu}_{2} \mathrm{ZnSnSe}_{4}$ and $\left.\mathrm{Cu}_{2} \mathrm{ZnSnS}_{4} \mathrm{NCs}\right){ }^{14}$

Concerning the homogeneous $\mathrm{Cu}_{2-x}\left(\mathrm{~S}_{y} \mathrm{Se}_{1-y}\right)$ alloy, only a few works have shown control over $y$ (i.e. over the relative $\mathrm{S} / \mathrm{Se}$ stoichiometry) in NCs and nanowires. ${ }^{3,15}$ It has been generally found that, for $\mathrm{Cu}_{2-x}\left(\mathrm{~S}_{y} \mathrm{Se}_{1-y}\right)$ alloys, physical vapor technique procedures preferentially yield hexagonal phase nanostructures, ${ }^{16}$ while wet chemical methods preferentially yield cubic phase nanostructures. ${ }^{9,17}$ In general, copper chalcogenide NCs of $\mathrm{Cu}_{2-x} \mathrm{~S}, \mathrm{Cu}_{2-x} \mathrm{Se}$ and $\mathrm{Cu}_{2-x} \mathrm{Te}$ have recently attracted much attention since they have been found to exhibit a plasmonic response in the near-infrared. ${ }^{18}$ This is due to the collective excitation of a large number of free carriers (holes) when the stoichiometry of copper is below 2 (that is, when " $x$ " in $\mathrm{Cu}_{2-x} \mathrm{~S}$, $\mathrm{Cu}_{2-x} \mathrm{Se}$ or $\mathrm{Cu}_{2-x} \mathrm{Te}$ is greater than zero). ${ }^{2,19-22}$ Also, it was found that the position and shape of the plasmon resonance peak in these NCs can be tuned by varying the degree of copper deficiency in the lattice (i.e. " $x$ ") by means of reversible oxidation/reduction processes. ${ }^{19,22}$ In a recent article on $\mathrm{Cu}_{2-x} \mathrm{Se}$ nanodisks, both in-plane and out-of-plane plasmon resonances were detected, in accordance with calculations based on the electrostatic approximation, ${ }^{23}$ which makes these plasmonic semiconductor NCs similar to noble metal NCs.

Developing a synthetic scheme for $\mathrm{Cu}_{2-x}\left(\mathrm{~S}_{y} \mathrm{Se}_{1-y}\right)$ alloy NCs based on a simple, reliable and environmentally friendly approach would yield valuable samples on which one could study 
the effect of composition and lattice symmetry on the plasmonic behavior of the NCs, or yet probe their response to various electrochemical processes, and which could be used as a starting point for accessing other alloy NCs via cation exchange. The limited number of current synthesis approaches to $\mathrm{Cu}_{2-x}\left(\mathrm{~S}_{y} \mathrm{Se}_{1-y}\right)$ nanostructures with tunable composition is most likely related to the fact that copper chalcogenides can form in a wide range of crystal structures and stoichiometric ratios of copper to the chalcogen $(\mathrm{S}, \mathrm{Se}) \cdot{ }^{24}$ Therefore, selecting slightly different reaction conditions with the aim of tuning " $y$ " in $\mathrm{Cu}_{2-x}\left(\mathrm{~S}_{y} \mathrm{Se}_{1-y}\right)$ could yield instead a compound with completely different stoichiometries of copper, sulfur and selenium, or could even produce mixtures of nanostructures of different crystal phases and compositions.

We report here an approach for the synthesis of $\mathrm{Cu}_{2-x}\left(\mathrm{~S}_{y} \mathrm{Se}_{1-y}\right)$ alloy $\mathrm{NCs}$ by employing elemental sulfur and also elemental selenium as chalcogenide sources, instead of the more commonly used (and more toxic) selenourea, at various $\mathrm{S}$ and Se concentrations and working with appropriate solvents and surfactants, namely octadecene (ODE) and oleylamine (OA). We could control the phase of the alloy NCs, which was either cubic or hexagonal, depending on the synthesis conditions. These differed from each other by the way in which chemicals were mixed and by the actual synthesis temperature. For cubic $\mathrm{Cu}_{2-x}\left(\mathrm{~S}_{y} \mathrm{Se}_{1-y}\right)$ alloy NCs, $y$ could be varied in the range $0.4-0.6$, while for hexagonal alloy NCs $y$ could be varied in the range $0.3-$ 0.7. In all the samples that we synthesized, the position of the plasmon peak in the near-infrared was mainly influenced by the degree of copper deficiency (i.e. " $x$ ") and to a lesser extent by the crystal phase of the NCs, while it did not appear to depend much on the S/Se stoichiometry. When the NCs were subjected to a cation exchange reaction with cadmium, they were converted to the corresponding $\mathrm{Cd}\left(\mathrm{S}_{y} \mathrm{Se}_{1-y}\right)$ NCs with retention of the symmetry of the lattice. This demonstrates how the $\mathrm{Cu}$-based alloy NCs can be used as a starting material for accessing, via cation exchange, other alloy NCs. We then carried out electrochemical lithiation experiments on one representative sample of $\mathrm{Cu}_{2-x}\left(\mathrm{~S}_{y} \mathrm{Se}_{1-y}\right)$ alloy NCs with $y=0.5$ and with cubic phase. The NCs were capable of undergoing a partially reversible lithiation in their crystal lattices, via a partial displacement reaction $(\mathrm{Cu}$ to $\mathrm{Li}$ and back), which makes them potentially interesting as anode materials in Li-ion batteries.

\section{Experimental section}

\section{Chemicals}

Trioctylphosphine oxide (TOPO, 99\%), trioctylphosphine (TOP, 97\%), copper(I) chloride ( $\mathrm{CuCl}, 99.999 \%)$, sulfur powder $(99+\%)$ and selenium powder (99.99) were obtained from Strem chem. Oleylamine (OA, tech. grade, 70\%), octadecene (ODE, tech. grade, 90\%), cadmium oxide (CdO, 99.999\%), and tetrachloroethylene (TCE, spectroscopic grade) were purchased from Sigma-Aldrich. Hexylphosphonic acid (HPA, 99\%) and octadecylphosphonic acid (ODPA, 99\%) were purchased from Polycarbon Industries. Cell components for coin type 2032 cells were purchased from Hohsen Corporation (Jp). Polypropylene microporous matrixes were purchased from Cellguard. Li metal foils were purchased from Good fellow (UK). Ethylene carbonate, diethylcarbonate, n-methyl-2-pyrrolidone, polyvinylidene difluoride (PVDF) and carbon powder were purchased from Aldrich. All the solvents used were thoroughly degassed.

\section{Synthesis procedures}

Preparation of the sulfur stock solution (solution A). $6.24 \mathrm{mmol}$ (200 $\mathrm{mg}$ ) of sulfur were dispersed in $25 \mathrm{ml}$ of ODE and the mixture was degassed in a three-neck flask for 1 hour at $80^{\circ} \mathrm{C}$. Then, under nitrogen, the temperature was raised to $180{ }^{\circ} \mathrm{C}$ and kept at this value for at least 1 hour, until the color of the solution became transparent yellow.

Preparation of the selenium stock solution (solution B). The solution B was prepared in similar way as for solution A: 3.13 mmol of selenium $(247 \mathrm{mg})$ were dissolved in $25 \mathrm{ml}$ of ODE. First, the solution was degassed for 1 hour at $80^{\circ} \mathrm{C}$; afterwards, under nitrogen, the temperature was slowly raised to $220^{\circ} \mathrm{C}\left(5^{\circ} \mathrm{C}\right.$ $\min ^{-1}$ ) and kept for $2 \mathrm{~h}$, until the solution became transparent yellow.

Synthesis of cubic $\mathbf{C u}_{2-x}\left(\mathbf{S}_{\boldsymbol{y}} \mathbf{S e}_{1-y}\right) \mathbf{N C}$ alloy NCs. $0.9 \mathrm{mmol}$ of copper(I) chloride $(90 \mathrm{mg} \mathrm{CuCl})$, weighed inside the glove box, were quickly transferred into a $25 \mathrm{ml}$ three-neck flask containing $10 \mathrm{ml}$ of $\mathrm{OA}$, and the mixture was further degassed under vigorous stirring and under vacuum for $1 \mathrm{~h}$ at $80^{\circ} \mathrm{C}$. Under nitrogen, the temperature was raised to $150{ }^{\circ} \mathrm{C}$ for $10 \mathrm{~min}$. Meanwhile, proper amounts of solution A and solution B were mixed in a $25 \mathrm{ml}$ flask and heated to $170{ }^{\circ} \mathrm{C}$ to prepare solution $\mathrm{C}$. The Se and $\mathrm{S}$ ratio was tuned to the required values, while their total amount was kept at $0.5 \mathrm{mmol}$ (see Table 1). As soon as the content of the copper chloride-oleylamine flask became transparent, the temperature was raised to $300{ }^{\circ} \mathrm{C}$. At this point, solution $\mathrm{C}(0.5 \mathrm{mmol}$ in total $)$ was injected into the flask. The reaction time was 5 minutes, after which the flask was allowed to cool down. When the temperature was about $60{ }^{\circ} \mathrm{C}, 5 \mathrm{ml}$ of toluene were added into the solution to prevent aggregation. The as-synthesized alloy NCs were washed with toluene and ethanol, and centrifuged twice at $3000 \mathrm{rpm}$. Finally, the NCs were dissolved in toluene.

Synthesis of hexagonal $\mathrm{Cu}_{2-x}\left(\mathrm{~S}_{y} \mathrm{Se}_{1-y}\right)$ alloy NCs. This was carried out basically following the same protocol as for the cubic alloy NCs, the only difference being that the solution $\mathrm{C}$ was not injected into the flask kept at $300{ }^{\circ} \mathrm{C}$, but instead it was mixed

Table 1 Amounts of precursors for the synthesis of the various alloy NCs

\begin{tabular}{llll}
\hline Cubic alloy & $\mathrm{Cu}$ & $\mathrm{S}$ & $\mathrm{Se}$ \\
\hline $\mathrm{Cu}_{2-x}\left(\mathrm{~S}_{0.40} \mathrm{Se}_{0.60}\right)$ & $1 \mathrm{mmol}$ & $0.125 \mathrm{mmol}$ & $0.375 \mathrm{mmol}$ \\
$\mathrm{Cu}_{2-x}\left(\mathrm{~S}_{0.49} \mathrm{Se}_{0.51}\right)$ & $1 \mathrm{mmol}$ & $0.166 \mathrm{mmol}$ & $0.333 \mathrm{mmol}$ \\
$\mathrm{Cu}_{2-x}\left(\mathrm{~S}_{0.62} \mathrm{Se}_{0.38}\right)$ & $1 \mathrm{mmol}$ & $0.25 \mathrm{mmol}$ & $0.25 \mathrm{mmol}$ \\
\hline Hexagonal alloy & $\mathrm{Cu}$ & $\mathrm{S}$ & $\mathrm{Se}$ \\
\hline $\mathrm{Cu}_{2-x}\left(\mathrm{~S}_{0.75} \mathrm{Se}_{0.25}\right)$ & $1 \mathrm{mmol}$ & $0.25 \mathrm{mmol}$ & $0.25 \mathrm{mmol}$ \\
$\mathrm{Cu}_{2-x}\left(\mathrm{~S}_{0.48} \mathrm{Se}_{0.52}\right)$ & $1 \mathrm{mmol}$ & $0.15 \mathrm{mmol}$ & $0.35 \mathrm{mmol}$ \\
$\mathrm{Cu}_{2-x}\left(\mathrm{~S}_{0.29} \mathrm{Se}_{0.71}\right)$ & $1 \mathrm{mmol}$ & $0.05 \mathrm{mmol}$ & $0.45 \mathrm{mmol}$ \\
\hline
\end{tabular}


with the solution contained in the flask at room temperature; then the resulting mixture was heated to $190^{\circ} \mathrm{C}$ and kept at this value for $1 \mathrm{~h}$. Cleaning procedures were the same as for the cubic alloy NCs.

\section{Cation exchange of $\mathrm{Cu}_{2-x}\left(\mathrm{~S}_{y} \mathrm{Se}_{1-y}\right)$ alloy $\mathrm{NCs}$ to $\mathrm{Cd}\left(\mathrm{S}_{y} \mathrm{Se}_{1-y}\right)$ alloy NCs}

$80 \mathrm{mg}$ of $\mathrm{CdO}, 90 \mathrm{mg}$ of HPA, $290 \mathrm{mg}$ of ODPA and $3 \mathrm{~g}$ of TOPO were degassed under vacuum at $120{ }^{\circ} \mathrm{C}$ for $90 \mathrm{~min}$. Afterwards the reaction flask was put under argon atmosphere and the temperature was set to $350{ }^{\circ} \mathrm{C}$ until all $\mathrm{CdO}$ was completely dissolved. $1.5 \mathrm{~g}$ of TOP were added to the flask and the temperature was allowed to recover to $350^{\circ} \mathrm{C}$. Subsequently, $300 \mu \mathrm{l}$ of the solution of $\mathrm{Cu}_{2-x} \mathrm{~S}_{1-y} \mathrm{Se}_{y} \mathrm{NCs}$ in toluene $(\sim 0.5$ to $2 \mu \mathrm{M})$ were injected and the temperature was kept at $350{ }^{\circ} \mathrm{C}$ for $5 \mathrm{~min}$, after which it was lowered slowly to room temperature and $3 \mathrm{ml}$ of toluene were added to the flask. The resulting $\mathrm{Cd}\left(\mathrm{S}_{1-y} \mathrm{Se}_{y}\right) \mathrm{NCs}$ were precipitated with methanol and redissolved in toluene.

\section{Transmission Electron Microscopy (TEM) analysis}

The samples were prepared by dropping dilute solutions of NCs onto carbon coated nickel grids, after which the specimens were placed in a pumping station in order to let the solvent evaporate. High Resolution TEM (HRTEM), High Angular Annular Dark Field (HAADF) Scanning TEM (STEM) and Energy Filtered TEM (EFTEM) measurements were performed with a JEOL JEM-2200FS microscope, equipped with a field emission gun working at an accelerating voltage of $200 \mathrm{kV}$, a CEOS spherical aberration corrector of objective lens allowing to reach a spatial resolution of $0.9 \AA$, and an in-column Omega filter. The chemical composition of several particles was determined by Energy Dispersive X-ray Spectroscopy (EDS) analysis performed in STEM mode, with a JED-2300 Si(Li) detector and using an electron probe of $0.7 \mathrm{~nm}$. The chemical quantification was calculated using the Cliff-Lorimer (or ratio) method, which is considered a good approximation for thin films. ${ }^{25}$ Elemental maps via EFTEM were acquired using a contrast aperture of about $10 \mathrm{mrad}$ to reduce aberrations, mostly chromatic, and using the three windows method. ${ }^{26}$ The elastic image (or zero-loss image) was acquired as a reference with a $10 \mathrm{eV}$ wide energy slit; then, chemical maps using the S L-edge (165 eV), Cd M-edge $(404 \mathrm{eV}), \mathrm{Cu}$ L-edge $(931 \mathrm{eV})$ and Se L-edge $(1436 \mathrm{eV})$ were acquired on the same area of zero-loss with energy slits of $20 \mathrm{eV}$, $30 \mathrm{eV}, 50 \mathrm{eV}$ and $60 \mathrm{eV}$, respectively. HRTEM observations and STEM-EDS analysis were performed using a JEOL analytical double tilt holder equipped with a beryllium low-background system.

\section{X-Ray Diffraction (XRD) measurements}

XRD spectra were recorded on a Smartlab $9 \mathrm{~kW}$ Rigaku diffractometer equipped with a copper rotating anode. The X-ray source was operated at $40 \mathrm{kV}$ and $150 \mathrm{~mA}$. A Gobel mirror was used to obtain a parallel beam and to suppress $\mathrm{Cu} K \beta$ radiation (1.392 $\AA$ ). The measurements were performed using a $\theta / 2 \theta$ scan.

\section{UV-Vis-NIR optical measurements}

UV-Vis-NIR absorption spectra were recorded with a UV-Visnear IR Cary 5000 (Varian) spectrophotometer. The NCs were dispersed in toluene.

\section{Elemental analysis}

The elemental analysis was carried out via Inductively Coupled Plasma Atomic Emission Spectroscopy (ICP-AES), using a iCAP 6500 Thermo spectrometer. Samples were dissolved in $\mathrm{HCl}-\mathrm{HNO}_{3} 3: 1$ (v/v).

\section{Electrochemical measurements and coin cell assembly}

All the electrochemical (EC) measurements were carried out using a PARSTAT2273 potentiostat/galvanostat. $\mathrm{Cu}_{2-x}\left(\mathrm{~S}_{y} \mathrm{Se}_{1-y}\right)$ alloy NCs (using $85 \mathrm{wt} \%$ of active NCs material) were mixed with carbon and PVDF in $\mathrm{N}$-methyl-2-pyrrolidone (degassed) in an argon filled glove box. The resulting composite was mixed well to obtain a homogeneous slurry; it was temporarily removed from the glove box and was then sonicated for $1 \mathrm{~h}$ in a sealed glass vial, after which it was transferred back into the glove box. The NC slurry was coated onto the current collector and dried at $120{ }^{\circ} \mathrm{C}$ for $24 \mathrm{~h}$. With these $\mathrm{Cu}_{2-x}\left(\mathrm{~S}_{y} \mathrm{Se}_{1-y}\right) \mathrm{NC}$ based electrodes, 2032 coin type cells were assembled using a pure Li metal disk electrode, serving both as counter and reference electrode. $1 \mathrm{M}$ lithium hexafluorophosphate in $1: 1$ ethylene carbonate and diethylcarbonate served as the electrolyte, and the electrodes were separated by layers of polypropylene.

\section{Results and discussion}

\section{Synthesis of cubic and hexagonal $\mathrm{Cu}_{2-x}\left(\mathrm{~S}_{y} \mathrm{Se}_{1-y}\right)$ alloy NCs}

Table 1 reports the synthesis conditions under which alloy NCs with various compositions and with controlled crystal phase were obtained. We will discuss first the cubic alloy NCs.

Fig. 1 reports TEM images (panels a-c) and XRD patterns (panels $\mathrm{d}$ and $\mathrm{e}$ ) of three samples of $\mathrm{Cu}_{2-x}\left(\mathrm{~S}_{y} \mathrm{Se}_{1-y}\right) \mathrm{NCs}$ prepared at different initial loadings of $\mathrm{S}$ and Se powders. The stoichiometry of the alloy NCs was assessed by elemental analysis on digested NC solutions via ICP-AES and by EDS on alloy NCs. The relative amounts of $\mathrm{S}$ and Se precursors used in the synthesis did not match however with the S and Se stoichiometry found in the NCs, due to the higher reactivity of S in ODE with respect to $\mathrm{Se}$ in this synthesis. Indeed, to achieve a $\mathrm{S}_{y} \mathrm{Se}_{1-y}$ stoichiometry in the NCs for a given value of $y$, a S : Se molar ratio lower than $y /(1-y)$ in the solution of reactants had to be used in the synthesis. With the present synthesis scheme, we could tune $y$ in the final NCs from 0.4 to 0.6 . When attempting to synthesize cubic NCs with $y$ outside this range, we faced the problem of side formation of $\mathrm{Cu}_{2} \mathrm{~S}$ or $\mathrm{Cu}_{2} \mathrm{Se}$ particles in addition to the alloy NCs.

The size and shape distribution was similar in all samples and the average diameters were $11.6 \pm 2.2 \mathrm{~nm}, 10.2 \pm 1.9 \mathrm{~nm}$ and $11.2 \pm 2.4 \mathrm{~nm}$ for the Se-rich, Se-medium and S-rich NCs, respectively. The XRD reflexions in the various samples (Fig. 1d) were close in position to those of the cubic fcc phase of $\mathrm{Cu}_{2-x} \mathrm{Se}$ 


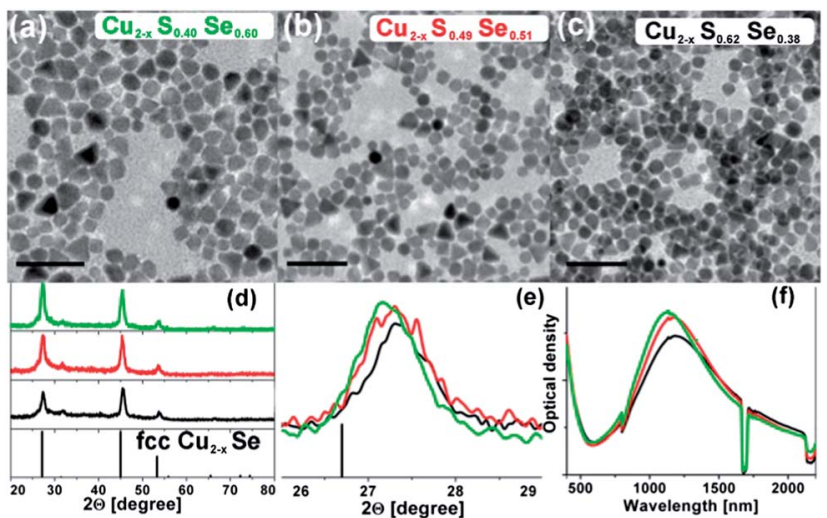

Fig. 1 (a-c) TEM survey images of three samples of $\mathrm{Cu}_{2-x}\left(\mathrm{~S}_{y} \mathrm{Se}_{1-y}\right)$ NCs with different $\mathrm{S}$ and Se stoichiometries, as determined by elemental analysis via ICP-AES. The scale bar corresponds to $50 \mathrm{~nm}$; (d) XRD patterns of the same samples, along with the bulk positions and intensities of fcc $\mathrm{Cu}_{2-x} \mathrm{Se}$ (berzelianite, JCPDS card 071-0044); (e) detail of the XRD patterns for the three samples near the (111) reflexion. In all samples the reflexion is shifted towards higher $2 \Theta$ with respect to fcc $\mathrm{Cu}_{2-x} \mathrm{Se}$; and (f) UV-VIS-NIR optical absorption spectra of the three samples of $\mathrm{Cu}_{2-x}\left(\mathrm{~S}_{y} \mathrm{Se}_{1-y}\right)$ alloy NCs in toluene after exposure to air for 4 days.

(berzelianite, JCPDS 071-0044), with only small shifts towards higher $2 \Theta$ with respect to fcc $\mathrm{Cu}_{2-x} \mathrm{Se}$ (Fig. 1e). This is compatible with the smaller lattice spacings of alloy NCs in which part of the Se ions in the lattice are replaced by the smaller $\mathrm{S}$ ions. The extent of the shift was related to the S stoichiometry and is in line with the decrease of unit cell size of cubic $\mathrm{Cu}_{2-x}\left(\mathrm{~S}_{y} \mathrm{Se}_{1-y}\right)$ NCs observed by Wang et al. in similar systems. ${ }^{15}$

Fig. 1f displays the UV-Vis-NIR optical absorption spectra of the three alloy NC samples of Fig. 1a-c, after 4 days of exposure to air. Initially, all the samples exhibited a weak and broad absorption that peaked at $1600 \mathrm{~nm}$, which shifted to shorter wavelengths upon exposure to air. After 4 days, the position of the band did not appear to shift further. In these oxidized samples, the $\mathrm{Cu}$ stoichiometry was $1.72,1.73$ and 1.78 (i.e. " $x$ " was $0.28,0.27$ and 0.22 ) for the Se-rich, Se-medium and S-rich NPs, respectively, as found by elemental analysis via STEMEDS. Here and in all the following elemental analyses of the various samples, the $\mathrm{Cu}$ stoichiometry was assessed via STEMEDS because elemental analysis via ICP-AES would also detect, besides the $\mathrm{Cu}$ deriving from digested alloy $\mathrm{NCs}, \mathrm{Cu}$ species related to $\mathrm{Cu}$ ions expelled from the alloy NCs upon oxidation. These species (including small copper oxide NCs) are difficult to separate quantitatively from the alloy NCs and can lead to overestimation of the $\mathrm{Cu}$ stoichiometry. STEM-EDS analysis carried out in situ in the electron microscope is instead more reliable because it is done on groups of NCs on the grid that are visibly free from copper oxide NCs. Also, by STEM-EDS a correct evaluation of $\mathrm{Cu}$ content, due to the presence of contaminants in the empty background regions, helps to avoid overestimation of the $\mathrm{Cu}$ stoichiometry of the alloy NCs. As shown in previous works for $\mathrm{Cu}_{2-x} \mathrm{~S}, \mathrm{Cu}_{2-x} \mathrm{Se}$, and $\mathrm{Cu}_{2-x} \mathrm{Te}$ NCs, upon exposure to oxygen these NCs indeed expel a part of the $\mathrm{Cu}$ atoms from their lattices, which leads to the formation of a large number of free carriers (holes) in the valence band. ${ }^{19,21,22}$
The collective excitation of these free carriers results in a surface plasmon resonance, to which the absorption signal in the NIR region of the optical absorption spectrum can be assigned. In the present case, the position and intensity of the plasmon band depended mainly on the $\mathrm{Cu}$ stoichiometry and not significantly on the $\mathrm{S}$ : Se ratio. Clearly, the intensities and the positions of the plasmon peaks in Fig. If are slightly different from each other. This might be due to several factors, above all small differences in the degree of oxidation of each sample (see further discussion in the text). In terms of energy though, since we are in the IR region, these are very small differences especially when compared to the significant shifts which occur when $e . g$. in $\mathrm{Cu}_{2-x} \mathrm{Se}$ the value of $x$ is significantly altered. ${ }^{19}$

Fig. 2a displays a high resolution HRTEM image of a representative $\mathrm{NC}$ of a cubic alloy sample with $\mathrm{S}: \mathrm{Se}$ atom ratio close to $0.5: 0.5$, i.e. $y=0.5$, oxidized under air for 4 days. The structure of the NC is cubic, as clearly ascertained by angular and vector relationships between the spots of reciprocal lattice in the

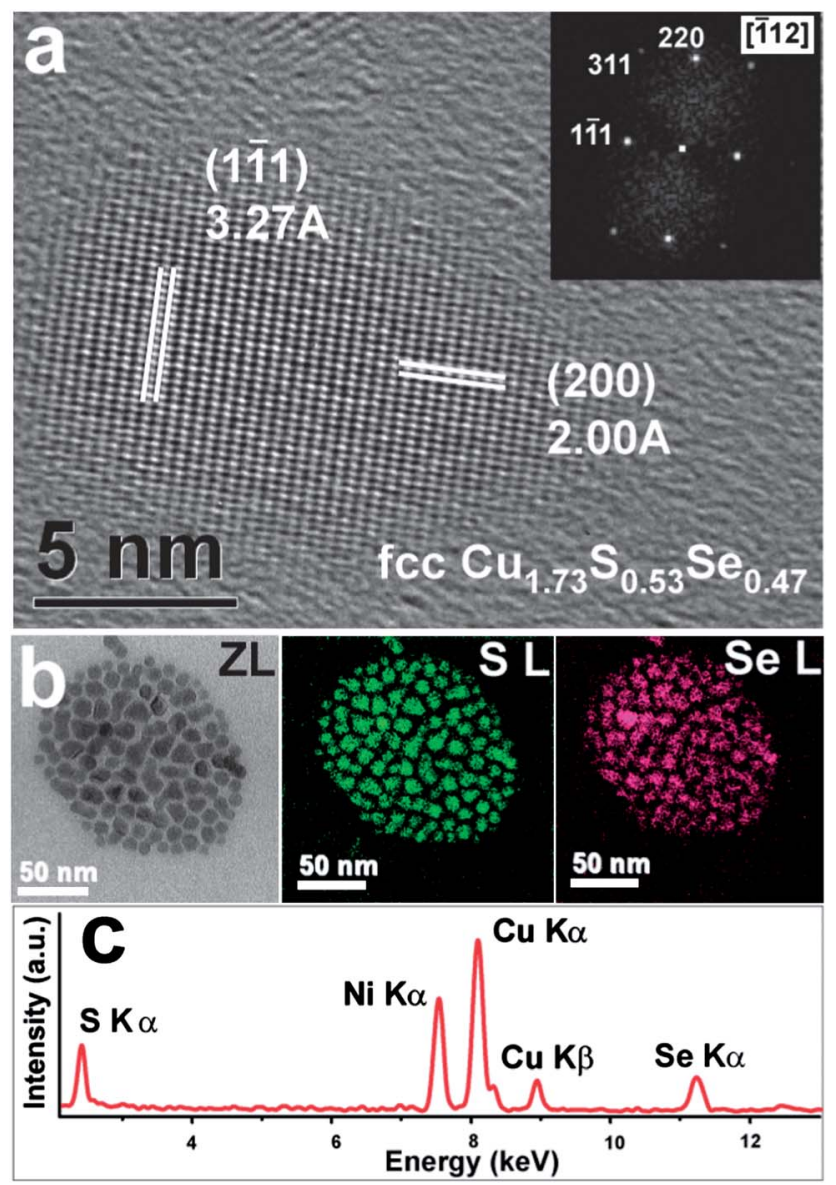

Fig. 2 (a) HRTEM image of a $\mathrm{Cu}_{2-x}\left(\mathrm{~S}_{y} \mathrm{Se}_{1-y}\right)$ alloy $\mathrm{NC}$ with fcc crystal structure exhibiting (111) and (220) lattice sets with measured $d$-spacings of $3.27 \AA$ and $2.00 \AA$, respectively and observed along the [11 12] zone axis, as confirmed by the 2D-FT pattern (inset); (b) chemical mapping via EFTEM: elastic filtered image (ZL) of several NCs and elemental maps obtained by filtering the $\mathrm{S}$ L-edge $(165 \mathrm{eV})$ and Se L-edge $(1436 \mathrm{eV})$; and (c) EDS spectrum of a group of NCs with $\mathrm{Cu}, \mathrm{S}$ and $\mathrm{Se} \mathrm{K} \alpha$ peaks, consistent with an atom ratio of $1.73: 0.53: 0.47$, respectively (here and in other EDS spectra shown in this work, Ni peaks originate from the $\mathrm{Ni}$ grid used for analysis). 
bi-dimensional Fourier transform (2D-FT) patterns (inset of Fig. 2a). Additional HRTEM data are shown in Fig. S1a and $\mathrm{b}$ of the ESI $\dagger$. We carried out an in situ chemical characterization via EFTEM mapping. Both the $\mathrm{S}$ and the Se signals were distributed homogeneously in all the particles, which rules out the formation of core/shell structures or particles of separated $\mathrm{Cu}_{2} \mathrm{Se}$ and $\mathrm{Cu}_{2} \mathrm{~S}$ phases as major components. In some of the particles however it was possible to notice an uneven distribution of $\mathrm{S}$ and Se due to local fluctuations of their concentrations. For example, while the Se L-edge signal confirmed the presence of Se in all NCs, in some NCs the Se distribution was not perfectly homogeneous (Fig. 2b). EDS elemental analysis via STEM mode yielded a $\mathrm{Cu}_{1.73} \mathrm{~S}_{0.53} \mathrm{Se}_{0.47}$ stoichiometry (Fig. 2c), which is comparable to that found by ICP-AES analysis for $\mathrm{S}$ and Se.

The hexagonal alloy NCs were instead synthesized by mixing, at room temperature, $\mathrm{OA}$, copper(I) chloride and a solution of $\mathrm{S}$ and Se precursors in ODE, and then by heating the mixture at $190{ }^{\circ} \mathrm{C}$ for $1 \mathrm{~h}$. When this synthesis approach was adopted, the NCs had a narrower size distribution than the cubic alloy NCs discussed above, with average diameters of $9.1 \pm 1.2 \mathrm{~nm}, 8.5 \pm$ $1.6 \mathrm{~nm}$ and $9.8 \pm 2.1 \mathrm{~nm}$ for the S-rich, Se-medium and Se-rich NPs, respectively (Fig. 3a-c). In this case, the XRD reflexions of the various samples were close in position to those of the hexagonal chalcocite phase of $\mathrm{Cu}_{2} \mathrm{~S}$ (JCPDS card 84-0209), with shifts towards smaller $2 \Theta$ with respect to hexagonal $\mathrm{Cu}_{2} \mathrm{~S}$ at increasing Se content (Fig. 3d-e). This is in line with the larger lattice spacings of alloy NCs in which part of the S ions in the lattice are replaced by the larger Se ions.

Fig. 3f reports the UV-Vis-NIR optical absorption spectra of the three alloy $\mathrm{NC}$ samples at different $\mathrm{S} / \mathrm{Se}$ stoichiometries, again after exposure to air for 4 days. ${ }^{27}$ Also in this case the absorption spectra of the various samples were very similar to each other. These optical spectra are also comparable to those of the alloy NCs of Fig. 1, which had similar $\mathrm{Cu}$ stoichiometries but had instead cubic crystal structure. On closer inspection, the plasmon positions in the hexagonal alloy NCs were however all systematically red-shifted by about $100 \mathrm{~nm}$ (around $90 \mathrm{meV}$ )

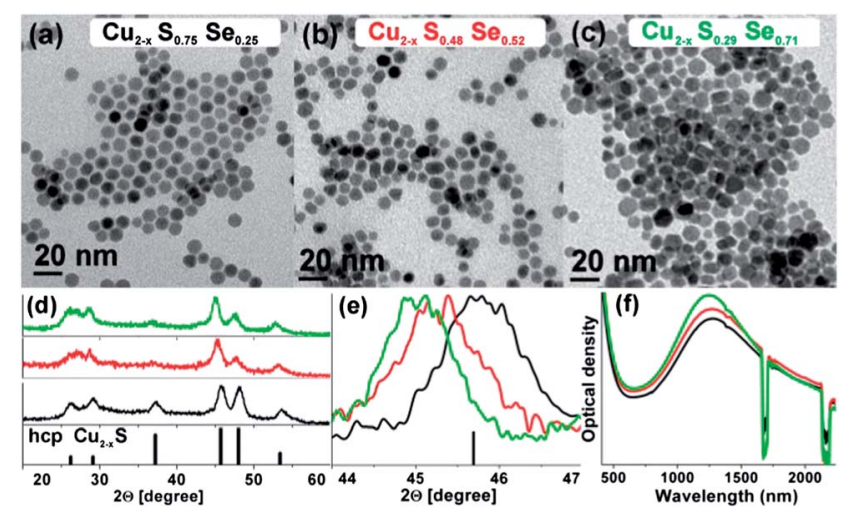

Fig. 3 (a-c) TEM images of three samples of hexagonal $\mathrm{Cu}_{2-x}\left(\mathrm{~S}_{y} \mathrm{Se}_{1-y}\right)$ alloy NCs with different $\mathrm{S}$ and Se stoichiometries, as determined by ICPAES elemental analysis; (d) XRD patterns of the three samples, along with the bulk positions and intensities of hexagonal $\mathrm{Cu}_{2} \mathrm{~S}$ (chalcocite, JCPDS card 84-0209); and (e) detail of the XRD patterns for the three samples near the (110) reflexion, showing how this shifts towards smaller $2 \Theta$ with respect to $\mathrm{Cu}_{2} \mathrm{~S}$ on increasing Se content; and (f) UV-VIS-NIR optical absorption spectra of the three samples. from those of the cubic alloy NCs. This can be due to small differences in $x$ among the two series of samples. Indeed, after the oxidation process, the $\mathrm{Cu}$ stoichiometry in these hexagonal alloys, as assessed via STEM-EDS, was 1.76, 1.78 and 1.82 (i.e. " $x$ " was $0.24,0.22$ and 0.18 ) for the S-rich, Se-medium and Serich NPs respectively. These are slightly higher values, on average, than for the cubic alloy NCs, which appears to indicate that the hexagonal alloy NCs tend to oxidize a bit slower than the cubic alloy NCs. On the other hand, one cannot exclude that the slightly different positions in plasmon resonance are in part due to differences in the crystal lattices. These could translate into different values of the effective mass of the free carriers for the two series of samples (which would impact the plasma frequency) and/or different density of trap states, which would influence the density of free carriers.

We can conclude therefore that in all the alloy NCs described in this work the spectral position and shape of the plasmonic absorption band appear to depend in the first instance on the $\mathrm{Cu}$ stoichiometry, but possibly also on the crystal phase, although apparently to a lower extent. The plasmonic response of these NCs is somewhat peculiar, if one recalls that the plasmon resonance of pure $\mathrm{Cu}_{2-x} \mathrm{~S}$ NCs is usually located at longer wavelengths, for example always above $1500 \mathrm{~nm}$ in the work by Jain et al. ${ }^{28} \mathrm{In}$ that case however Jain et al. estimated $x=0.07$ for oxidized $\mathrm{Cu}_{2-x} \mathrm{~S},{ }^{28}$ i.e. a much lower degree of $\mathrm{Cu}$ deficiency than what can be achieved in $\mathrm{Cu}_{2-x} \mathrm{Se}$ and in the present alloy NCs. This means that the alloy NCs synthesized by us are much closer to $\mathrm{Cu}_{2-x} \mathrm{Se}$ than to $\mathrm{Cu}_{2-x} \mathrm{~S}$ with respect to their tendency to expel copper, even for a sulfur rich (S: Se ratios as high as $3: 1)$ alloy sample.

A HRTEM image and relative 2D-FT pattern of a single NC from a sample of alloy NCs oxidized under air for 4 days are reported in Fig. 4a. The data are consistent with a hexagonal chalcocite-like structure. Also for these hexagonal NCs, additional HRTEM data are shown in Fig. S1c and d of the ESI $\dagger$. EFTEM mapping of the S L-edge and Se L-edge confirmed the presence of both $\mathrm{S}$ and Se in all NCs (Fig. 4b). Here too in some NCs the Se distribution was not entirely homogeneous, as evidenced by the Se L-edge signal map. For this sample, STEMEDS elemental quantification on several NCs yielded a composition consistent with $\mathrm{Cu}_{1.76} \mathrm{~S}_{0.63} \mathrm{Se}_{0.37}$ stoichiometry (Fig. 4c).

It is important to stress here that in all the NC samples discussed above, the particle size should affect the plasmon position only to a very minor extent. The NCs studied here are indeed in a size range for which the electrostatic approximation holds (the size of the particle is smaller than $1 / 10$ of the wavelength of the incoming field), and in this size regime the plasmon resonance is independent of particle size for plasmonic particles active in the NIR. Indeed our NC sizes are definitely smaller than 100$120 \mathrm{~nm}$, where retardation effects should start playing a role. On the other hand, it is also known, both in the case of metals and for degenerate semiconductors, that for particle sizes smaller than $10 \mathrm{~nm}^{29}$ a slight broadening and red-shift of the plasmon resonance can be seen, due to surface dephasing effects. This effect is significant however only for very small particles (i.e. 5$6 \mathrm{~nm}$ and smaller, see also Luther et $a .^{21}$ for the specific case of $\mathrm{Cu}_{2-x} \mathrm{~S}$ nanoparticles). Since our NCs have sizes around $10 \mathrm{~nm}$ or above, surface dephasing effects should not be relevant. We can then conclude that $\mathrm{NC}$ size has a very minor effect on the position of the plasmon resonance in our case. 


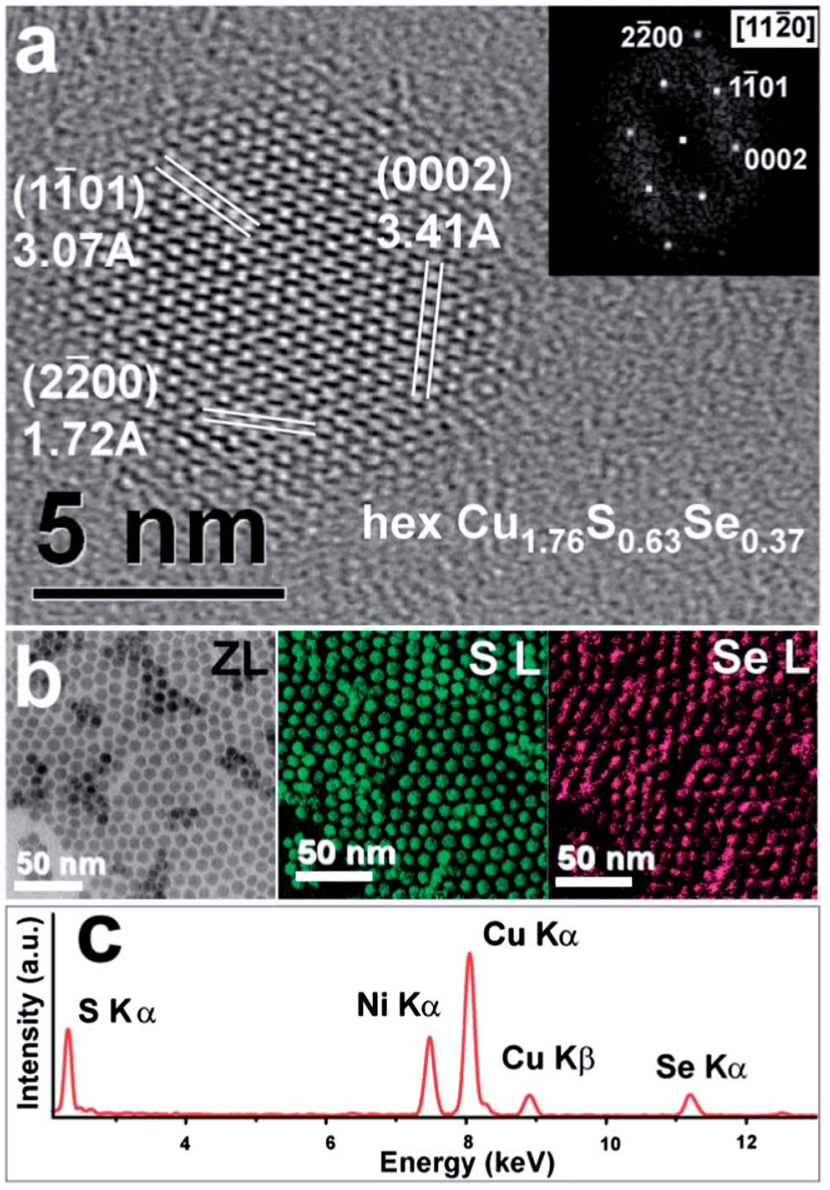

Fig. 4 (a) HRTEM image of a hexagonal alloy NC displaying (1101), (2200) and (0002) lattice sets with measured $d$-spacings of $3.07 \AA, 1.72 \AA$ and $3.41 \AA$, respectively, forming angular relationships consistent with the [1120] axial projection. Indeed the angle [0002] $[1 \overline{1} 01]$ is $63^{\circ}$, and the angle [1 $1 \overline{1} 01]^{\wedge}[2 \overline{2} 00]$ is $27^{\circ}$, as confirmed by the 2D-FT pattern (inset); (b) chemical mapping via EFTEM reporting the elastic filtered image (ZL) of several NCs and the corresponding S and Se elemental distribution obtained by filtering the $\mathrm{S}$ L-edge $(165 \mathrm{eV})$ and Se L-edge $(1436 \mathrm{eV})$; and (c) EDS spectrum of several Cu-based hexagonal NCs reporting the $\mathrm{K} \alpha$ peaks of $\mathrm{Cu}, \mathrm{S}$ and $\mathrm{Se}$ whose intensities are consistent with atom ratios of $1.76: 0.63: 0.37$, respectively.

\section{Cation exchange}

Many works have shown that ionic NCs can undergo cation exchange reactions while preserving their actual shape, size and anion sublattice. ${ }^{28,30}$ Especially for $\mathrm{Cu}_{2-x} \mathrm{Se} \mathrm{NCs}$ this has been exploited for preparing sphalerite CdSe NCs in a size regime (for example above $10 \mathrm{~nm}$ ) that was previously inaccessible by colloidal synthesis. ${ }^{31}$ Also our $\mathrm{Cu}_{2-x}\left(\mathrm{~S}_{\mathrm{y}} \mathrm{Se}_{1-y}\right)$ NCs underwent complete cation exchange when exposed to excess $\mathrm{Cd}^{2+}$ ions. This was done by injecting a solution of alloy NCs in a mixture of TOPO and alkylphosphonic acids, in which $\mathrm{CdO}$ had been previously dissolved, heated at $350{ }^{\circ} \mathrm{C}$. Moreover, since the lattice symmetry of the original $\mathrm{Cu}$-based $\mathrm{NCs}$ could either be cubic or hexagonal, depending on the synthesis approach, the $\mathrm{Cd}\left(\mathrm{S}_{y} \mathrm{Se}_{1-y}\right) \mathrm{NCs}$ conserved this phase information, so they were either cubic sphalerite or hexagonal wurtzite.

HRTEM analysis performed on two representative samples of $\mathrm{Cd}\left(\mathrm{S}_{y} \mathrm{Se}_{1-y}\right)$ NCs confirmed the symmetries of the pristine
$\mathrm{Cu}$-based particles (cubic and hexagonal, respectively see Fig. 5a and d). Additional HRTEM data on Cd-based cubic and hexagonal alloy NCs are shown in Fig. S2 of the ESI $\dagger$. Elemental quantification (via STEM-EDS on several NCs) excluded the presence of a mixture of $\mathrm{CdSe}$ and $\mathrm{CdS} \mathrm{NCs}$ and confirmed instead the presence of alloy $\mathrm{Cd}\left(\mathrm{S}_{y} \mathrm{Se}_{1-y}\right) \mathrm{NCs}$. In the specific case of the sample displayed in Fig. 5, " $y$ " was equal to 0.44 for the cubic NCs and 0.64 for the hexagonal NCs (Fig. 5c and f).

We actually noticed that the Cd-based alloy NCs were slightly richer (by a few per cent) in sulfur than the starting $\mathrm{Cu}$-based alloy NCs (those of Fig. 1). Apart from the error associated with the EDS measurements, this slight but systematic enrichment in $\mathrm{S}$ stoichiometry might be due to the selective extraction of selenium from the lattice. The extraction of $\mathrm{S}$ and Se from metal sulfide and selenide nanoparticles by TOP has been reported recently by Sines and $\mathrm{Schaak}^{32}$ In the present case, it is likely that, during the cation exchange reaction, the TOP involved in this conversion removes selectively a small fraction of Se from the $\mathrm{NC}$ lattice, thus enriching the final sample in S. XRD patterns of cubic Cd-exchanged alloys NCs, of which a representative HRTEM image is displayed in Fig. 5a, exhibited reflexions consistent with a sphalerite structure, where the main (111), (220) and (311) diffraction peaks fell between the corresponding peaks of CdS and CdSe pure phases with the same structure (Fig. 5b). This is quite clear by looking in detail the region of the 111 reflexion of the Cd-based alloy NCs (Fig. 6e). On the other hand,
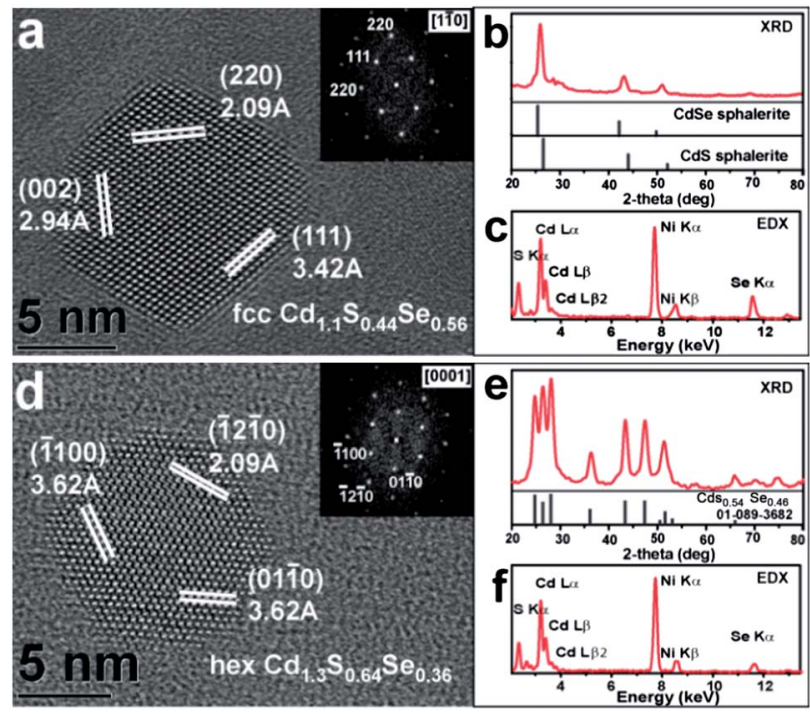

Fig. 5 (a) HRTEM image of a cubic $\mathrm{Cd}_{1.1} \mathrm{~S}_{0.44} \mathrm{Se}_{0.56}$ alloy $\mathrm{NC}$ exhibiting the (220), (002) and (111) lattice sets with measured $d$-spacing of $2.09 \AA$, $2.94 \AA$ and $3.42 \AA$ respectively, seen along the [110] zone axis, as confirmed from the 2D-FT pattern (inset); (b) XRD pattern of cubic Cdbased alloy NCs, consistent with a sphalerite-like structure with the diffraction peaks between the CdS and CdSe fcc phases; (c) EDS spectrum of Cd-based cubic alloy NCs showing only the peaks of $\mathrm{Cd}, \mathrm{S}$ and Se; (d) HRTEM image of a hexagonal $\mathrm{Cd}_{1.3} \mathrm{~S}_{0.64} \mathrm{Se}_{0.36} \mathrm{NC}$ and a 2D-FT pattern (inset) consistent with the [0001] axial projection, displaying the (1100) and (1210) lattice sets with measured $d$-spacings of $3.62 \AA$ and $2.09 \AA$, respectively; (e) XRD pattern of hexagonal Cd-based alloy NCs, compatible with the $\mathrm{CdS}_{0.54} \mathrm{Se}_{0.46}$ phase (JCPDS card 089-3682); and (f) EDS spectrum of Cd-based hexagonal alloy NCs showing only the peaks of $\mathrm{Cd}, \mathrm{S}$ and Se. 
the hexagonal Cd-based alloy NCs, of which a representative HRTEM image is displayed in Fig. 5d, were characterized by diffraction patterns that could be indexed according to the wurtzite-like phase with $\mathrm{CdS}_{0.54} \mathrm{Se}_{0.46}$ composition (JCPDS card 089-3682, see Fig. 5e). STEM-EDS chemical quantification of Cd-based alloy NCs yielded Cd stoichiometry higher than unity. This might be due to the formation of a surface layer richer in $\mathrm{Cd}$ in these NCs.

Fig. $6 f$ displays the UV-Vis absorption spectra for a series of Cd-based cubic alloy $\mathrm{NCs}$ obtained from their respective $\mathrm{Cu}$ based alloy NCs by cation exchange. Due to the relatively large diameter of all the NCs, which is much larger than the Bohr exciton diameter of both $\mathrm{CdSe}$ and $\mathrm{CdS}^{33}$ (the Bohr exciton diameter for the alloy is presumably somewhere in between), no significant contribution from size quantization is expected in all these samples. Thus the shift in absorption onset can be clearly assigned to differences in composition of the various samples. As expected, the band gap for the samples that are richer in sulfur was larger and thus the absorption onset was shifted towards higher energies (shorter wavelengths). In the case of the hexagonal Cd-based alloy NCs, for reasons that are unclear so far, cation exchange was not always successful. In various experiments, the initial nanocrystals were degraded upon exchange and yielded mixtures of irregularly shaped nanoparticles of varying composition (representative microscopy images for this case are shown in Fig. S3 of the ESI $\dagger$ ). ${ }^{27}$ The interpretation of this effect is still ongoing.

\section{Electrochemical lithiation}

In lithium ion batteries, one key requisite of electrodes is their ability to sustain reversible intercalation, insertion or displacement reactions with $\mathrm{Li}^{+}$ions during charge/discharge. ${ }^{34}$ Among the various copper chalcogenides, copper sulfides $\left(\mathrm{CuS}, \mathrm{Cu}_{2} \mathrm{~S}\right)$, copper selenides ( $\mathrm{CuSe}, \mathrm{CuSe}_{2}, \mathrm{Cu}_{2} \mathrm{Se}$ ) and copper oxides $\left(\mathrm{CuO}, \mathrm{Cu}_{2} \mathrm{O}\right)$ have been shown to be potential electrode materials for $\mathrm{Li}^{+}$ion battery applications. ${ }^{35-37}$ It was also seen that the charge/discharge cycles from cells with those materials occurred

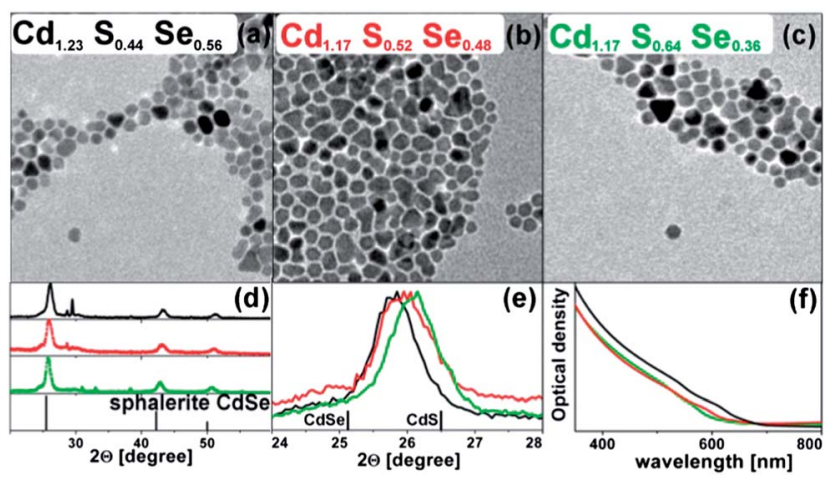

Fig. 6 TEM images (a-c) and XRD patterns (d-e) of cubic $\mathrm{Cd}\left(\mathrm{S}_{y} \mathrm{Se}_{1-y}\right)$ alloy NCs obtained via cation exchange from the cubic $\mathrm{Cu}_{2-x}\left(\mathrm{~S}_{y} \mathrm{Se}_{1-y}\right)$ alloy NCs; (e) is a zoom-in of the 111 peaks of the XRD patterns displayed in panel (d). The positions are all between the 111 peaks of the bulk phases of sphalerite CdSe and sphalerite CdS: depending on the Se/S ratio the reflex shifts (black line: $\mathrm{Se} / \mathrm{S}=60 / 40$, red line $\mathrm{Se} / \mathrm{S}=50 / 50$, green line: $\mathrm{Se} / \mathrm{S}=40 / 60$ ); and (f) UV-VIS absorption spectra of $\mathrm{Cd}\left(\mathrm{S}_{y} \mathrm{Se}_{1-y}\right)$ alloy NCs with different compositions prepared by cation exchange. basically through displacement/conversion (partial) reactions with $\mathrm{Li}^{+}$ions ${ }^{35,36,38}$ rather than through topotactic intercalation/ de-intercalation of $\mathrm{Li}^{+}$ions. ${ }^{39}$ This inevitably leads to a considerable irreversible capacity and indeed a rapid fading of the reversible capacity was observed in all such cases. Presumably, non-reversible alloying during $\mathrm{Li}^{+}$insertion, drastic structural distortions (due to conversion processes involving non-reversible products), and the presence of non-decomposable lithiated phases (during the oxidation) were among the main factors responsible for such capacity loss. In order to optimize lithium reaction kinetics of electrode materials based on NCs, apart from NC size and shape effects, another important parameter that can be tuned is the chemical composition, through the synthesis of alloys or of intermetallic compounds. In general, electrodes based on active alloy particles appear to display interesting features, for example in terms of a buffer effect (one of the elements of the alloy can alleviate the volume change taking place upon lithiation-delithiation), in terms of extra plasticity of the particle or even regarding enhanced ionic conductivity and $\mathrm{Li}^{+}$ storage. ${ }^{40}$ Therefore, also the alloy NCs developed in this work might offer interesting electrochemical properties and may possibly represent new anode materials among the $\mathrm{Cu}$ chalcogenides reported so far.

We studied the electrochemical lithiation on these alloyed NCs in coin type half cells $v s$. Li metal. We used freshly prepared, nonoxidized cubic $\mathrm{Cu}_{2-x}\left(\mathrm{~S}_{0.5} \mathrm{Se}_{0.5}\right)$ NCs (therefore with $\mathrm{Cu}$ stoichiometry close to 2). A TEM image from the composite slurry used to prepare the electrodes is reported in Fig. 7a, which reveals that the $\mathrm{Cu}_{2-x}\left(\mathrm{~S}_{0.5} \mathrm{Se}_{0.5}\right)$ NCs were randomly dispersed (the original NCs used to prepare the composite are displayed in the inset). The lithiation stages $\left(\mathrm{Li}^{+}\right.$ion insertion/desertion) along the potential scan could be followed via cyclic voltammetry (CV). From the CV curves, $\mathrm{Li}^{+}$ions started to lithiate the $\mathrm{NC}$ surface at a potential of $1.9 \mathrm{~V}$, as evidenced by a well resolved peak at $1.5-1.3 \mathrm{~V}$, as shown in Fig. 7b. After this first insertion potential, a very broad peak with steep reduction current was observed, indicating a continuous lithiation process in steps on the NCs. At more negative potentials (from $0.8 \mathrm{~V}$ to $0.05 \mathrm{~V}$ ) one can identify the deep discharge zone, where the $\mathrm{Li}^{+}$ion flux upon substitution appeared to induce a complete reduction of copper and its expulsion, ${ }^{41}$ which in fact partly constitutes the conversion processes. This trend seemed very similar to that of electrodes based either on "only" copper selenide or "only" copper sulfide, ${ }^{36,42}$ and therefore a simplified cell reaction may be expressed as follows:

$\mathrm{Cu}_{2}\left(\mathrm{~S}_{y} \mathrm{Se}_{1-y}\right)+2 \mathrm{Li}^{+} \Leftrightarrow 2 \mathrm{Cu}+\mathrm{Li}_{2}\left(\mathrm{~S}_{y} \mathrm{Se}_{1-y}\right)\left(\right.$ or $\left.\mathrm{Li}_{x} \mathrm{~S}_{y}+\mathrm{Li}_{x} \mathrm{Se}_{1-y}\right)$

Also, the overall mechanism is comparable to that of transition metal-oxide electrodes, ${ }^{43}$ where the metal was reversibly reduced. It is likely however that severe structural distortions in the NCs, during deep lithiation, could reduce the cyclability of the cells. At the same time, due to the enhanced reactivity of $\mathrm{NCs}$, the formation of a surface passivating film through the reduction of electrolyte species to some extent is also inevitable below potentials of $0.4 \mathrm{~V}$, which normally increases the surface resistance. A typical galvanostatic discharge curve at a current density at $0.2 \mathrm{~mA}$, as reported in the inset of Fig. $7 \mathrm{~b}$, reveals that the NC electrodes exhibit a first sloping voltage plateau at about 

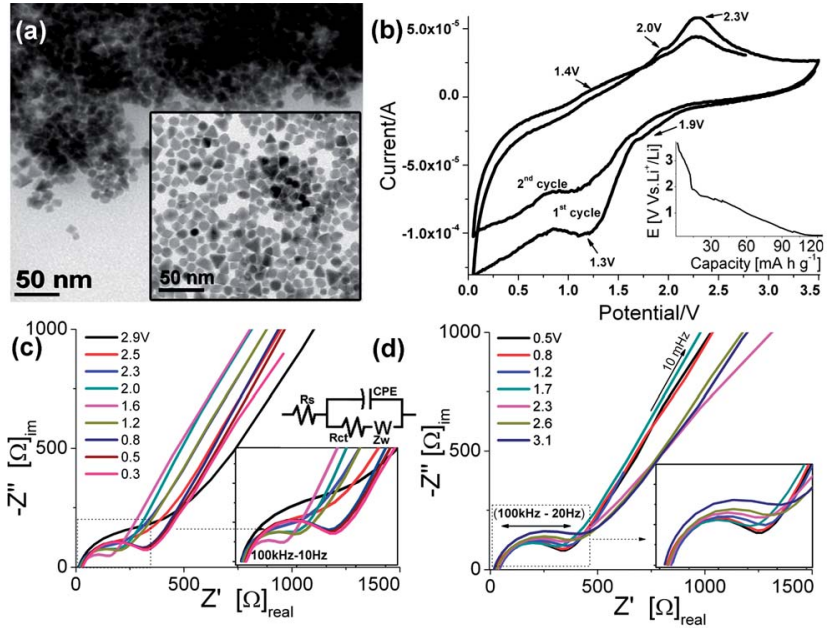

Fig. 7 (a) TEM image of the composite slurry used for the preparation electrodes, whereas the inset is a TEM image of the starting $\mathrm{Cu}_{2-x}\left(\mathrm{~S}_{0.5} \mathrm{Se}_{0.5}\right)$ alloy NCs; (b) cyclic voltammogram (CV) of $\mathrm{Cu}_{2-x}\left(\mathrm{~S}_{0.5} \mathrm{Se}_{0.5}\right)$ alloy nanocrystals at $1 \mathrm{mV} \mathrm{s}{ }^{-1}$ vs. $\mathrm{Li}$, the inset image reports the discharge curve from $3.5 \mathrm{~V}$ to $0.5 \mathrm{~V}$, where a voltage plateau is evident; (c) and (d) report the electrochemical impedance spectra, from which one can extract more details of the electrochemical processes at the electrode/electrolyte, for both lithiated (c) and de-lithiated NCs (d). The insets of (c) and of (d) are magnifications of the high frequency regions.

$2.3 \mathrm{~V}$, followed by a second main plateau between $1.8 \mathrm{~V}$ and $0.9 \mathrm{~V}$, as these two processes were mainly observed in broad peaks from $\mathrm{CV}$ data. From these data ${ }^{27}$ it is conceivable that the potential window of $0.8 \mathrm{~V}-2.8 \mathrm{~V}$ could be beneficial for this material in terms of cyclability, since at potentials below $0.5 \mathrm{~V}$ (deep discharge zone) the inserted $\mathrm{Li}^{+}$ions seem unlikely to be completely extracted, due to possible alloying in the host lattices. On the reverse scan, the oxidation process could be correlated to the broad peaks at about $1.4 \mathrm{~V}$ and $2.3-2.5 \mathrm{~V}$, which indicate the de-lithiation of the NCs. The peak potentials, in the following cycles, stabilized after a slight positive shift in the forward scan, pointing to a better stability of the $\mathrm{NC}$ electrodes in the latter scans, as shown in Fig. S5 of the ESI†.

We additionally performed electrochemical impedance spectroscopy (EIS), which is a powerful electroanalytical tool for studying electrode processes. The complex impedance spectra as a function of the different states of charge/discharge contain information such as variations in the kinetics of lithiation/delithiation across the electrode/electrolyte interface. ${ }^{44}$ Impedance spectra of the cells were recorded at room temperature between $100 \mathrm{kHz}$ and $10 \mathrm{mHz}$ with an AC amplitude of $20 \mathrm{mV} \mathrm{S}^{-1}$. The cells were discharged/charged to different potentials and the electrode impedance was then measured. Fig. $7 \mathrm{c}$ reports the impedance spectra in a Nyquist plot, from which it is possible to extract information on the different electrochemical processes that take place at the electrode/electrolyte interface and that contribute to the total electrode impedance. It could be noted that the shape of the impedance curves (in the $100 \mathrm{kHz}-20 \mathrm{~Hz}$ frequency region) gradually changed to pronounced semi-circles after the insertion of $\mathrm{Li}^{+}$ions at a potential of $\sim 1.8 \mathrm{~V}$ to $1.9 \mathrm{~V}$ (in agreement with $\mathrm{CV}$ data) and the semi-circles have also enlarged diameter below the deep lithiation zone, which was from $0.8 \mathrm{~V}$ to $0.05 \mathrm{~V}$, as observed by $\mathrm{CV}$.
The overall impedance response observed for these NC-based electrodes could be explained on the basis of a generalized equivalent circuit as reported in the inset of Fig. 7c. Based on the Nyquist plot, the intercept on the $Z^{\prime}$ (real axis) in the high frequency region corresponds to the electrolyte resistance $\left(R_{\mathrm{e}}\right)$ and the semicircle could be assigned to the presence of a solid electrolyte interface (SEI) and therefore of a charge-transfer resistance $\left(R_{\mathrm{ct}}\right)$ across the electrode/electrolyte interface for the transport of $\mathrm{Li}^{+}$ions. The observed $R_{\mathrm{ct}}$ varied monotonously upon progressive lithiation. However, the slight variations in diameter of these semi-circles (see the inset in Fig. 7c and S6 of the ESI $\dagger$ ) for such a deep lithiating zone are indicative of variations in the ionic diffusion on the $\mathrm{NCs}^{45}$ as a result of different phases of lithiated NCs. At this stage, some degree of conversion processes of the NCs (into mainly non-reversible products) could not be excluded.

The low frequency region in the Nyquist plot was governed by ionic diffusion processes, in particular the linear portion (spike) with a $45^{\circ}$ slope corresponds to the resistive component (Warburg impedance, $Z_{\mathrm{w}}$ ) associated with a solid-state ionic diffusion of $\mathrm{Li}^{+}$ions. ${ }^{46}$ In Fig. $7 \mathrm{~d}$, the impedance spectra also reports the de-lithiation processes on those NCs, where the observed response was probably due to removal of $\mathrm{Li}^{+}$ions through the decomposition of lithiated phases and the SEI surface films, as this was observed as a strong oxidation peak from CV data.

\section{Conclusions}

Overall, we could prepare cubic and hexagonal $\mathrm{Cu}_{2-x}\left(\mathrm{~S}_{y} \mathrm{Se}_{1-y}\right)$ alloy $\mathrm{NCs}$ with similar $\mathrm{Cu} / \mathrm{S} / \mathrm{Se}$ stoichiometries by tuning the synthesis conditions, as ascertained from extensive structural and compositional characterization. The plasmonic response of the particles was dependent mainly on the copper stoichiometry and, surprisingly, was very similar to that of $\mathrm{Cu}_{2-x} \mathrm{Se} \mathrm{NCs}$ even for sulfur-rich alloy NCs. Starting from the various alloy NCs we could access also Cd-based alloy NCs via cation exchange. The $\mathrm{Cu}_{2-x}\left(\mathrm{~S}_{y} \mathrm{Se}_{1-y}\right) \mathrm{NCs}$ were found to undergo fast lithiation/delithation processes, leading to a partial displacement/conversion reaction $(\mathrm{Cu}$ to $\mathrm{Li}$ and back).

\section{Acknowledgements}

The authors acknowledge financial support from European Union through the FP7 starting ERC grant NANO-ARCH (contract number 240111).

\section{Notes and references}

1 J. Choi, N. Kang, H. Y. Yang, H. J. Kim and S. U. Son, Chem. Mater., 2010, 22, 3586-3588; S. Deka, A. Genovese, Y. Zhang, K. Miszta, G. Bertoni, R. Krahne, C. Giannini and L. Manna, J. Am. Chem. Soc., 2010, 132, 8912-8914; S. C. Riha, D. C. Johnson and A. L. Prieto, J. Am. Chem. Soc., 2010, 133, 1383-1390; Y. Wu, C. Wadia, W. Ma, B. Sadtler and A. P. Alivisatos, Nano Lett., 2008, 8, 2551-2555; I. Kriegel, J. Rodrí guez-Fernández, E. D. Como, A. A. Lutich, J. M. Szeifert and J. Feldmann, Chem. Mater., 2011, 23, 1830-1834; R. J. Mendelsberg, G. Garcia, H. Li, L. Manna and D. J. Milliron, J. Phys. Chem. C, 2012, DOI: 10.1021/jp302732s.

2 Y. X. Zhao, H. C. Pan, Y. B. Lou, X. F. Qiu, J. J. Zhu and C. Burda, J. Am. Chem. Soc., 2009, 131, 4253-4261. 
3 J. Xu, Y. B. Tang, X. Chen, C. Y. Luan, W. F. Zhang, J. A. Zapien, W. J. Zhang, H. L. Kwong, X. M. Meng, S. T. Lee and C. S. Lee, Adv. Funct. Mater., 2010, 20, 4190-4195.

4 A. A. Yadav and E. U. Masumdar, Electrochim. Acta, 2011, 56, 6406 6410; K. Yu, J. Y. Ouyang, Y. G. Zhang, H. T. Tung, S. Q. Lin, R. A. L. Nagelkerke, D. Kingston, X. H. Wu, D. M. Leek, D. Wilkinson, C. S. Li, I. G. Chen and Y. Tao, ACS Appl. Mater. Interfaces, 2011, 3, 1511-1520; W. Zhang and X. Zhong, Inorg. Chem., 2011, 50, 4065-4072; R. J. Zheng, Y. M. Fang, S. F. Qin, J. Song, A. H. Wu and J. J. Sun, Sens. Actuators, B, 2011, 157, 488-493; M. G. Panthani, V. Akhavan, B. Goodfellow, J. P. Schmidtke, L. Dunn, A. Dodabalapur, P. F. Barbara and B. A. Korgel, J. Am. Chem. Soc., 2008, 130, 16770-16777; J. Zhang, R. Xie and W. Yang, Chem. Mater., 2011, 23, 3357-3361.

5 T. K. Todorov, K. B. Reuter and D. B. Mitzi, Adv. Mater., 2010, 22, E156-E159; Q. Guo, G. M. Ford, H. W. Hillhouse and R. Agrawal, Nano Lett., 2009, 9, 3060-3065; C. Steinhagen, M. G. Panthani, V. Akhavan, B. Goodfellow, B. Koo and B. A. Korgel, J. Am. Chem. Soc., 2009, 131, 12554-12555; T. Tanaka, D. Kawasaki, M. Nishio, Q. Guo and H. Ogawa, Phys. Status Solidi C, 2006, 3, 2844-2847; Q. Guo, G. M. Ford, W.-C. Yang, B. C. Walker, E. A. Stach, H. W. Hillhouse and R. Agrawal, J. Am. Chem. Soc., 2010, 132, 17384-17386.

6 M. Kuno, K. A. Higginson, S. B. Qadri, M. Yousuf, S. H. Lee, B. L. Davis and H. Mattoussi, J. Phys. Chem. B, 2003, 107, 57585767.

7 M. Wang, G. T. Fei, Y. G. Zhang, M. G. Kong and L. D. Zhang, $A d v$. Mater., 2007, 19, 4491-4494; H. Y. Xu, Y. Liang, Z. A. Liu, X. T. Zhang and S. K. Hark, Adv. Mater., 2008, 20, 3294-3297.

$8 \mathrm{H}$. Wei, Y. Su, S. Chen, Y. Lin, Z. Yang, X. Chen and Y. Zhang, J. Mater. Chem., 2011, 21, 12605-12608.

9 L. A. Swafford, L. A. Weigand, M. J. Bowers, J. R. McBride, J. L. Rapaport, T. L. Watt, S. K. Dixit, L. C. Feldman and S. J. Rosenthal, J. Am. Chem. Soc., 2006, 128, 12299-12306.

10 J. Akhtar, M. Afzaal, M. Banski, A. Podhorodecki, M. Syperek, J. Misiewicz, U. Bangert, S. J. O. Hardman, D. M. Graham, W. R. Flavell, D. J. Binks, S. Gardonio and P. O'Brien, J. Am. Chem. Soc., 2011, 133, 5602-5609.

11 M.-Y. Chiang, S.-H. Chang, C.-Y. Chen, F.-W. Yuan and H.-Y. Tuan, J. Phys. Chem. C, 2011, 115, 1592-1599.

12 K. Suekuni, K. Tsuruta, T. Ariga and M. Koyano, J. Appl. Phys., 2011, 109, 083709

13 S. C. Riha, B. A. Parkinson and A. L. Prieto, J. Am. Chem. Soc., 2011, 133, 15272-15275.

14 J.-J. Wang, J.-S. Hu, Y.-G. Guo and L.-J. Wan, NPG Asia Materials, 2012, 4, e2, DOI: 10.1038/am.2012.1032; A. Singh, H. Geaney, F. Laffir and K. M. Ryan, J. Am. Chem. Soc., 2012, 134, 29102913; M. D. Regulacio, C. Ye, S. H. Lim, M. Bosman, E. Ye, S. Chen, Q.-H. Xu and M.-Y. Han, Chem.-Eur. J., 2012, 18, 31273131.

15 J.-J. Wang, D.-J. Xue, Y.-G. Guo, J.-S. Hu and L.-J. Wan, J. Am. Chem. Soc., 2011, 133, 18558-18561.

16 A. L. Pan, H. Yang, R. B. Liu, R. C. Yu, B. S. Zou and Z. L. Wang, J. Am. Chem. Soc., 2005, 127, 15692-15693; L. Junpeng, S. Cheng, Z. Minrui, N. Mathews, L. Hongwei, C. Gin Seng, Z. Xinhai, S. G. Mhaisalkar and S. Chorng Haur, J. Phys. Chem. C, 2011, 115, 19538-19545.

17 J. Ouyang, M. Vincent, D. Kingston, P. Descours, T. Boivineau, M. B. Zaman, X. Wu and K. Yu, J. Phys. Chem. C, 2009, 113, $5193-5200$.

18 Y. Zhao and C. Burda, Energy Environ. Sci., 2012, 5, 5564-5576.

19 D. Dorfs, T. Hartling, K. Miszta, N. C. Bigall, M. R. Kim, A. Genovese, A. Falqui, M. Povia and L. Manna, J. Am. Chem. Soc., 2011, 133, 11175-11180.

20 C. M. Hessel, V. P. Pattani, M. Rasch, M. G. Panthani, B. Koo, J. W. Tunnell and B. A. Korgel, Nano Lett., 2011, 11, 2560-2566.

21 J. M. Luther, P. K. Jain, T. Ewers and A. P. Alivisatos, Nat. Mater., 2011, 10, 361-366.

22 I. Kriegel, C. Y. Jiang, J. Rodríguez-Fernández, R. D. Schaller, D. V. Talapin, E. Da Como and J. Feldmann, J. Am. Chem. Soc., 2012, 134, 1583-1590.

23 S.-W. Hsu, K. On and A. R. Tao, J. Am. Chem. Soc., 2011, 133, 19072-19075.
24 S. Kashida, W. Shimosaka, M. Mori and D. Yoshimura, J. Phys. Chem. Solids, 2003, 64, 2357-2363.

25 B. Fultz and J. M. Howe, Transmission Electron Microscopy and Diffractometry of Materials, Springer-Verlag, Berlin Heidelberg, 2nd edn, 2002.

26 R. F. Egerton, Electron Energy Loss Spectroscopy in the Electron Microscope, Plenum Press, New York, 2nd edn, 1996.

27 Additional details on materials and methods are available in the ESI $\uparrow$.

28 P. K. Jain, L. Amirav, S. Aloni and A. P. Alivisatos, J. Am. Chem. Soc., 2010, 132, 9997-9999.

29 R. Krahne, G. Morello, A. Figuerola, C. George, S. Deka and L. Manna, Phys. Rep., 2011, 501, 75-221.

30 D. H. Son, S. M. Hughes, Y. D. Yin and A. P. Alivisatos, Science, 2004, 306, 1009-1012; B. Sadtler, D. O. Demchenko, H. Zheng, S. M. Hughes, M. G. Merkle, U. Dahmen, L. W. Wang and A. P. Alivisatos, J. Am. Chem. Soc., 2009, 131, 5285-5293; B. Zhang, Y. Jung, H.-S. Chung, L. V. Vugt and R. Agarwal, Nano Lett., 2009, 10, 149-155; D. Kelly, A. Singh, C. A. Barrett, C. O'Sullivan, C. Coughlan, F. R. Laffir, C. O'Dwyer and K. M. Ryan, Nanoscale, 2011, 3, 4580-4583; H. B. Li, R. Brescia, R. Krahne, G. Bertoni, M. J. P. Alcocer, C. D'Andrea, F. Scotognella, F. Tassone, M. Zanella, M. De Giorgi and L. Manna, ACS Nano, 2012, 6, 1637-1647; K. Miszta, D. Dorfs, A. Genovese, M. R. Kim and L. Manna, ACS Nano, 2011, 5, 71767183.

31 H. B. Li, M. Zanella, A. Genovese, M. Povia, A. Falqui, C. Giannini and L. Manna, Nano Lett., 2011, 11, 4964-4970.

32 I. T. Sines and R. E. Schaak, J. Am. Chem. Soc., 2010, 133, 1294 1297.

33 S. V. Gaponenko, Optical Properties of Semiconductor Nanocrystals, Cambridge University Press, 1998.

34 P. G. Bruce, B. Scrosati and J.-M. Tarascon, Angew. Chem., Int. Ed., 2008, 47, 2930-2946.

35 Y. Han, Y. Wang, W. Gao, Y. Wang, L. Jiao, H. Yuan and S. Liu, Powder Technol., 2011, 212, 64-68.

36 M.-Z. Xue, Y.-N. Zhou, B. Zhang, L. Yu, H. Zhang and Z.-W. Fu, J. Electrochem. Soc., 2006, 153, A2262-A2268.

37 Y. Zhao and C. Burda, Energy Environ. Sci., 2012, 5, 5564-5576.

38 O. Crosnier and L. F. Nazar, Electrochem. Solid-State Lett., 2004, 7, A187-A189; S. Grugeon, S. Laruelle, R. Herrera-Urbina, L. Dupont, P. Poizot and J.-M. Tarascon, J. Electrochem. Soc., 2001, 148, A285A292.

39 S.-i. Nishimura, G. Kobayashi, K. Ohoyama, R. Kanno, M. Yashima and A. Yamada, Nat. Mater., 2008, 7, 707-711.

40 Y. Li and J. Li, J. Phys. Chem. C, 2008, 112, 14216-14219; Y. Kim, N. Arumugam and J. B. Goodenough, Chem. Mater., 2007, 20, 470-474; C. S. Johnson, N. Li, C. Lefief, J. T. Vaughey and M. M. Thackeray, Chem. Mater., 2008, 20, 6095-6106; D. Dambournet, K. W. Chapman, P. J. Chupas, R. E. Gerald, N. Penin, C. Labrugere, A. Demourgues, A. Tressaud and K. Amine, J. Am. Chem. Soc., 2011, 133, 13240-13243; A. Rong, X. P. Gao, G. R. Li, T. Y. Yan, H. Y. Zhu, J. Q. Qu and D. Y. Song, J. Phys. Chem. B, 2006, 110, 14754-14760.

$41 \mathrm{~J}$. Cabana, L. Monconduit, D. Larcher and M. R. Palacín, $A d v$. Mater., 2010, 22, E170-E192; V. Bodenez, L. Dupont, L. Laffont, A. R. Armstrong, K. M. Shaju, P. G. Bruce and J. M. Tarascon, J. Mater. Chem., 2007, 17, 3238-3247.

42 J. S. Chung and H. J. Sohn, J. Power Sources, 2002, 108, 226-231.

43 Y.-S. Hu, Y.-G. Guo, W. Sigle, S. Hore, P. Balaya and J. Maier, Nat. Mater., 2006, 5, 713-717; P. Poizot, S. Laruelle, S. Grugeon, L. Dupont and J. M. Tarascon, Nature, 2000, 407, 496-499.

44 M. V. Reddy, T. Yu, C. H. Sow, Z. X. Shen, C. T. Lim, G. V. Subba Rao and B. V. R. Chowdari, Adv. Funct. Mater., 2007, 17, 2792-2799.

45 M. K. Balapanov, I. G. Gafurov, U. K. Mukhamed'yanov, R. A. Yakshibaev and R. K. Ishembetov, Phys. Status Solidi B, 2004, 241, 114-119; M. K. Balapanov, I. B. Zinnurov and U. K. Mukhamed'yanov, Russ. J. Electrochem., 2007, 43, 585-589.

46 R. Ruffo, S. S. Hong, C. K. Chan, R. A. Huggins and Y. Cui, J. Phys. Chem. C, 2009, 113, 11390-11398; A. Paolella, C. George, M. Povia, Y. Zhang, R. Krahne, M. Gich, A. Genovese, A. Falqui, M. Longobardi, P. Guardia, T. Pellegrino and L. Manna, Chem. Mater., 2011, 23, 3762-3768. 